\title{
A OFICINA NA ESCOLA COM PROFESSORAS COMO UM DISPOSITIVO PARA O CUIDADO DE SI
}

Caroline Foletto Bevilaqua

Prefeitura Municipal de Canoas

Rosemarie Gartner Tschiedel

Universidade Federal do Rio Grande do Sul - UFRGS

\begin{abstract}
Resumo
A experiência narrada neste artigo integra a escrita de uma dissertação de mestrado que buscou analisar como se produzem as experiências de cuidado de si com professoras. A pesquisa percorreu algumas escolas estaduais e constituiu-se como uma pesquisa-intervenção, amparada em referenciais da Análise Institucional e da Cartografia. Também se utilizou o diário de campo como uma ferramenta para o registro das afetações e observações do campo de pesquisa. Essa experiência considerou a importância da construção de espaços coletivos de análise e problematizações, assim como a oferta de momentos de cuidado de si para as professoras. A pesquisa afirmou a relevância de ofertarem-se vivências atentas à produção de subjetividades no espaço escolar, no sentido de investir-se em propostas mais inventivas e práticas pedagógicas menos atreladas às burocracias.
\end{abstract}

Palavras-chave: cuidado de si; professoras; escola; subjetividade; oficinas.

\begin{abstract}
The experience narrated in this article presents part of the results from a master's degree dissertation that analyzed how self-care experiences with teachers take place. The research happened in some state schools and it was an intervention research supported by references of Institutional Analysis and Cartography. A field diary was used as a tool to register assignments and observations concerning the research field. This experience considered the importance of the construction of collective spaces for analysis and problematizations as well as the offering of selfcare moments for the teachers. The research showed the relevance of offering experiences for the production of subjectivities in the school space to invest in propositions that are more inventive and less bureaucratic pedagogical practices.
\end{abstract}

Keywords: self-care; teachers; school; subjectivity; offices. 


\section{Introdução}

As análises apresentadas nesse artigo derivam de uma pesquisa de mestrado ${ }^{1}$ que propôs analisar como professoras produzem o cuidado de si na escola. $\mathrm{O}$ aumento do número de professoras afastadas da sala de aula por motivos de adoecimento ${ }^{2}$, assim como os relatos de várias supervisoras escolares preocupadas com o contexto de sofrimento das professoras no trabalho impulsionaram a escrita desse percurso de pesquisa.

A pesquisa ocorreu em uma escola estadual da rede pública de Porto Alegre/RS e contou com algumas experiências piloto em outras duas escolas do mesmo território. As escolas são parceiras do Programa Saúde na Escola e do Programa de Extensão Viver Melhor na Escola: educação, saúde e cidadania e localizam-se no território de abrangência da Unidade Básica de Saúde Santa Cecília, serviço de referência do Hospital de Clínicas de Porto Alegre.

As reuniões com estes programas anunciaram a demanda escolar para um trabalho junto aos professores da rede estadual. O cenário no qual essas escolas estão imersas denuncia a precarização do trabalho do professor através do parcelamento salarial, das longas jornadas de trabalho e da coerção por parte do governo frente à greves e paralisações.

Abordou-se o cuidado de si como uma possibilidade de experenciar modos de vida no âmbito escolar que sejam mais inventivos e menos amarrados às burocracias escolares. Além disso, interessou pensar o cuidado de si como um potencializador das relações entre as pessoas, proporcionando a atenção a si, mas também, um retorno à realidade na forma de ação (GALVÃO, 2014). Nesse sentido, apostou-se em um cuidado de si atrelado às práticas de liberdade e que inspirasse transformações no dia a dia escolar.

As práticas de cuidado de si podem auxiliar na produção de outras experiências com as professoras e na problematização dos atuais processos de subjetivação, os quais são tensionados por forças que elegem o individualismo, a competição e modos-indivíduo como possibilidades de vida. O cuidado de si nos apresenta a possibilidade de compartilhamento de experiências, memórias, histórias e escritas. Narrativas diversas que elegem diferentes histórias, mas produzem agenciamentos coletivos e transversalidade nos espaços e nas relações.

É nesse sentido que se insiste na produção do cuidado de si como compartilhamento de experiências. Uma experiência, que segundo Larrosa (2002), é aquilo que nos passa, que nos acontece. Para o autor, inspirado em Walter Benjamin, o conceito de experiência é cada vez mais raro devido à falta de tempo do sujeito contemporâneo, um consumidor insaciável das informações rápidas e que está sempre insatisfeito. Para Foucault (2012) a produção de uma escrita é também a produção de experiência consigo e com aqueles com quem se compartilha essa escrita revelando os movimentos do pensamento.

A experiência em educação também passa por caminhos nebulosos, na medida em que a vivência de experiências que nos toquem se torna rara. $\mathrm{Na}$ escola "o currículo se organiza 
em pacotes cada vez mais numerosos e cada vez mais curtos. Com isso, também em educação estamos sempre acelerados e nada nos acontece" (LARROSA, 2002, p.23).

As subjetividades fabricadas nos contextos escolares são produto histórico de relações de saber-poder estabelecidas entre os sujeitos. A história, o contexto social, econômico, político e cultural, o espaço-tempo e a arquitetura escolar configuram uma trama que atravessa as subjetividades das professoras.

Esses aspectos apareceram em diversos momentos da pesquisa e a oferta de oficinas acompanha a proposta de pesquisa-intervenção com apoio dos referenciais da Análise Institucional e alguns conceitos da Cartografia. A análise das experiências refletiu na produção de um esquema que incluiu linhas estéticas, jurídico-normativas e políticas, que auxiliou na produção da oficina como um dispositivo.

Nesse sentido, a oficina e suas linhas, juntamente com uma ampla pesquisa a respeito da configuração do campo de análise - a educação - possibilitou mapear as produções subjetivas do espaço escolar. Nesse processo, as histórias e memórias das professoras compuseram um arranjo de subjetividades que auxiliaram no desenho das experiências de possíveis cuidado de si de acordo com a realidade em que as participantes estão inseridas.

A pesquisa alertou para a importância da produção de práticas pedagógicas atentas às subjetividades escolares e que criem condições para a expressão dos sujeitos que compõem a escola. Nesse sentido, o cuidado de si pode auxiliar na produção de sujeitos mais atentos a si e aos outros, conduzindo a um compartilhamento de experiências que transcende as engrenagens da maquinaria escolar.

\section{O cuidado de si entre a antiguidade e a contemporaneidade}

Neste trabalho optou-se por resgatar os estudos do filósofo Michel Foucault para produzir um diálogo com o cuidado de si. Como objeto para suas fundamentações, o filósofo busca nos gregos o amparo para pensar a produção de um modo de vida ético. Uma vida produzida ao mesmo tempo como resistência e obra de arte, singular, na qual estão impressas as experiências, lutas e potência de criação de seu autor. Em algum momento, os gregos parecem ter produzido uma invenção de si que escapa do que é conhecido hoje. É um modo de vida em um ritmo diverso daquele que se vivencia atualmente no qual a urgência toma conta das experiências.

Ao acompanhar Michel Foucault em seus estudos sobre a cultura grega encontrar-se-á em alguns momentos, indivíduos cada vez mais preocupados com os aspectos privados de sua existência. $\mathrm{O}$ autor descreve um individualismo crescente no período helenístico e romano. Como parte desse contexto, Foucault (2014), relata o declínio das cidades-estado, enquanto entidades autônomas, a partir do séc. III a.C, o que causa em parte, um recuo da vida política e retiro para a valorização da existência pessoal e vida privada. $O$ filósofo também elenca três aspectos para caracterizar o indivíduo grego em sua obra A história da Sexualidade - O cuidado de si. 
Inicialmente, Foucault fala de uma atitude individualista, descrita a partir da valorização atribuída ao indivíduo em sua singularidade, marcando também, certa independência deste em relação ao grupo ou instituições ao qual ele pertence. Em segundo lugar, salienta a valorização da vida privada, aspecto que se aproxima do primeiro, na medida em que se destaca a importância concedida às relações familiares, às formas de atividade doméstica e aos interesses patrimoniais. Por fim, cita a intensidade das relações consigo que convoca "a se tornar a si próprio como objeto de conhecimento e campo de ação para transformar-se, corrigir-se, purificar-se e promover a própria salvação" (FOUCAULT, 2014, p.48).

Por mais que algumas técnicas e práticas de si exigissem momentos solitários e de recolhimento, o cuidado de si constituía-se como uma prática social, na medida em que, posteriormente, ascendiam a uma dimensão coletiva (ESCÓSSIA, 2014). Este contexto está localizado em um momento histórico muito distante do presente, porém possibilita o diálogo com o que se tem vivenciado atualmente no Brasil, a exemplo da retirada de direitos sociais da população e a precarização dos serviços públicos e das relações com trabalhadores. Visualiza-se um movimento a serviço do neoliberalismo econômico que convoca as pessoas a "cuidarem de si" e a praticarem uma atenção aos seus interesses individuais. A partir da leitura de Veiga-Neto (2013), entende-se que a escola é considerada no contexto neoliberal como uma máquina encarregada de fabricar novas subjetividades, na medida em que o neoliberalismo pode ser considerado um modo de estar na vida. Nesta doutrina, os processos econômicos não são naturais e "devem ser continuamente ensinados, governados, regulados, dirigidos, controlados” (VEIGA-NETO, 2013, p.38-9).

Pensa-se o cuidado de si na contramão dos processos neoliberais, a fim de marcar a sua dimensão coletiva, na medida em que implica relações com o mundo e com aqueles que fazem parte deste contexto. Ao contrário do que o modelo capitalista propõe, ou seja, a subjetivação dos sujeitos como "modo-indivíduo", o cuidado de si auxilia a pensar na produção de territórios existenciais que possam resgatar redes de apoio e potencializar a noção de coletivo, tecendo resistências à produção de relações individualistas. Assim, a atividade consagrada a si mesmo "não constitui um exercício de solidão, mas sim uma verdadeira prática social" (FOUCAULT, 1985, p.47).

O cuidado de si grego - que é diferente do cuidado de si contemporâneo, mesmo guardando semelhanças - também instigava a publicização deste cuidado. Como exemplo, têm-se as correspondências trocadas entre companheiros ou "uma escrita de si que atenua os perigos da solidão" (FOUCAULT, 2012, p.129). Para o autor, os hupomnêmatas poderiam assumir formas diversas, mas "constituíam uma memória material das coisas lidas, ouvidas ou pensadas; ofereciam-nas assim, qual tesouro acumulado, à releitura e à meditação ulterior [...]. Ou para ultrapassar esta ou aquela circunstância difícil (um luto, um exílio, a ruína, a desgraça)" (FOUCAULT, 2012, p.131).

A função dos hupomnêmatas era a de auxiliar na produção de um discurso, um material ao qual se pudesse recorrer quando se necessitasse. Estes propõem "captar o já dito; reunir aquilo que se pôde ouvir ou ler, e isto com uma finalidade que não é nada menos que a constituição de si" (FOUCAULT, 2012, p.145). O papel da escrita é o de 
constituir um corpo, transformando-se no próprio corpo do escritor, o corpo "daquele que, ao transcrever as suas leituras, se apossou delas e fez sua a respectiva verdade" (p.148). Com as correspondências, também se afirma uma proposta de mostrar-se para o outro, com uma abertura de si mesmo que se dá ao outro (FOUCAULT 2012). Ao escrever e compartilhar, o indivíduo dispõe de tempo e abre espaço em suas vidas para o encontro.

No momento em que retoma a Apologia de Sócrates, Foucault afirma que "o cuidado de si é uma espécie de aguilhão que deve ser implantado na carne dos homens, cravado na sua existência e constitui um princípio de agitação, um princípio de movimento, um princípio de permanente inquietude no curso da existência" (FOUCAULT, 2014, p.9). Nos antigos, o cuidado de si, ou a epiméleia heautoû, é uma atitude para consigo, com os outros, com o mundo, mas é também uma forma de atenção e olhar. Para isso, "cuidar de si mesmo implica que se converta o olhar, que se conduza do exterior para [...] 'si mesmo"”. O cuidado de si constitui um conjunto de práticas pelas quais "nos assumimos, nos modificamos, nos purificamos, nos transformamos e nos transfiguramos" (FOUCAULT, 2014, p.12).

Assim, o cuidado de si como ferramenta conceitual pode auxiliar a fortalecer as relações consigo e com o coletivo no espaço escolar, a fim de que novas conquistas sejam realizadas, sem necessariamente cristalizar as práticas por longos períodos de tempo. $\mathrm{Na}$ composição do cuidado de si, o que está em jogo é a formação de uma askesis, ou seja, a cultura de si compõe um conjunto de práticas e "como um bom lutador, devemos aprender exclusivamente aquilo que nos permitirá resistir aos acontecimentos que podem se produzir" (FOUCAULT, 2014, p.449).

Gros (2012) ressalta as relações estabelecidas por Foucault (2014) entre sujeito e verdade, atentando então, para a subjetivação do cuidado de si, a qual segundo o autor, pode ser denominada de ética. Gros (2012) afirma que o olhar para si não é decifração, mas um caminho para "reagir de maneira correta face aos acontecimentos do mundo [...]. O sujeito engendrado por este retorno sobre si não é um sujeito do conhecimento introspectivo, mas um sujeito que age e age conforme seus princípios de ação" (GROS, 2012, p.323). Para Foucault (2012), o cuidado de si é justamente o conhecimento de si, mas também, o conhecimento de princípios que funcionam como verdades, ou seja, a constituição de uma ética no sujeito.

$\mathrm{Na}$ Antiguidade, o cuidado de si consistia em um privilégio político, econômico e social. Consequentemente, este estava restrito a alguns grupos que teriam tempo e condições de cuidar de si. É em Alcibíades que Foucault (2014) encontra uma caracterização do cuidado de si como uma ferramenta que possibilitaria transformar "seu status privilegiado, sua primazia estatutária em ação política, em governo efetivo dele próprio sobre os outros" (FOUCAULT, 2014, p.32). Porém, Foucault afirma que a Alcibíades falta, justamente, a tékhne (governo de si e dos outros), condição que caracterizaria possível inferioridade diante dos rivais no que se refere ao exercício do poder.

Incluía-se nesse cenário o cuidado de si preocupado com os exercícios físicos, as dietas, as meditações e o preparo para o sono. Atualmente, encontra-se um cuidado de si 
que, além de conter alguns desses elementos, pode ser utilizado como um mapeamento ultramoderno das doenças e moléstias que afligem os corpos. Inúmeros exames são realizados para monitorar a saúde, assim como procedimentos são utilizados para manter o corpo sempre jovem. Neste sentido, contemporaneamente, o cuidado de si parece estar encoberto por uma medicalização da vida, infinitos testes e diagnósticos que pretendem controlar a população e sua saúde (PRADRO FILHO, 2009).

Se o cuidado de si se diferencia de um posicionamento egoísta e narcísico, implicando necessariamente, "uma ação para com o outro" (GALVÃO, 2014, p.159); ele pode ser tomado como um aliado do processo de subjetivação contemporâneo, oferecendo pistas para outros modos de vida possíveis. Quando se tenta marcar esta posição, esta funciona como uma tentativa de explorar as multiplicidades que habitam o mundo, sem tentar afirmar que esta é a melhor opção para que as pessoas experimentem suas vidas.

Desta forma, a ideia consiste em traçar linhas de fuga, que escapem minimamente, aos efeitos da captura das subjetividades capitalísticas que conformam os sujeitos aos padrões pré-estabelecidos. O cuidado de si grego e o cuidado de si com as professoras não possuem um viés de normalização da vida, mas insistem na constituição de uma dobra no processo de subjetivação.

\section{Um contorno para a metodologia}

O desenvolvimento da pesquisa ${ }^{3}$ ocorreu no período de 2015 a 2017 e contou com a parceria do Programa Saúde na Escola e do Programa de Extensão Viver Melhor na Escola: educação, saúde e cidadania. A construção desta pesquisa aconteceu em meio à participação das pesquisadoras em diferentes espaços de discussão e formação (reuniões do Programa Saúde na Escola, supervisões coletivas dos estudantes de graduação, visitas às escolas, etc.). Após algum tempo de imersão no campo ocorreram pedidos das escolas para que se trabalhasse sobre o cuidado do professor. A temática despertou interesse pela possibilidade de pensar em um cuidado de si com as professoras.

Para mapear os interesses dos professores com relação às oficinas, utilizou-se um questionário construído pelo Programa de Extensão Viver Melhor na Escola. O questionário possibilitava conhecer alguns aspectos de saúde e trabalho dos professores. Após a análise desse instrumento, percebeu-se que os interesses permeavam: a) trabalhos com o corpo: relaxamentos, alongamentos, dança; b) trabalhos artísticos: desenho, pintura, cinema; c) Formação de professores.

Os encontros da oficina configuraram-se a partir de arranjos com dança, música, relaxamentos, alongamentos, escrita, cinema e fotografia. A pesquisa percorreu três escolas estaduais pertencentes ao território de atuação da UBS e propôs experiências piloto para convidar os professores a participar das oficinas.

A proposta inicial consistiu em oito encontros, uma vez por semana, durante o horário de trabalho das professoras (combinado previamente com as gestões escolares). O conjunto de encontros da oficina realizou-se apenas em uma dessas escolas e contou com a 
participação de 5 a 7 professoras por semana, totalizando cinco encontros. As participantes possuíam idades que variavam de 30 a 60 anos e trabalhavam desde as séries iniciais até os anos finais do Ensino Fundamental.

$\mathrm{Na}$ expectativa de uma pesquisa participativa e construída com as participantes, encontrou-se abrigo na pesquisa-intervenção. A escolha pelo método de intervenção relacionou-se com o fato de que este "consiste em um dispositivo que se propõe a analisar uma situação coletiva” (LOURAU, 1993, p.30). Dessa forma, o interesse localizou-se na construção de um campo de análise que ofereça visibilidade das forças, tensões e relações estabelecidas com o cuidado de si das professoras na escola. As oficinas consistiram no dispositivo criado para possibilitar a construção desse campo de intervenção.

O diário de campo foi utilizado como instrumento de registro, através da escrita implicada, dos acontecimentos, detalhes e afetações geradas pelo campo de pesquisa. A partir dele, foi possível identificar tensões e problematizações para a análise e a restituição.

Outro conceito caro à pesquisa-intervenção é a restituição, a qual é entendida como uma ferramenta para que se possa falar "de algumas coisas que, em geral, são deixadas à sombra" (LOURAU, 1993, p.51). Neste momento, é importante devolver alguns aspectos considerados relevantes para a própria transformação das relações estabelecidas no espaço escolar e que orientem para a análise coletiva deste contexto. A atenção se volta para a enunciação das "coisas" e não sua denúncia (LOURAU, 1993).

Coimbra e Nascimento (2007) auxiliam a pensar no processo de sobreimplicação do trabalho na escola. Em seus estudos sobre algumas práticas desenvolvidas no Juizado da Infância e Adolescência e no Conselho Tutelar, no Rio de Janeiro, as autoras afirmam que dois aspectos contribuem para o fortalecimento da sobreimplicação: o acúmulo de tarefas e a produção de urgências. Ambas as características, também observadas durante o processo da pesquisa, parecem atender à lógica capitalista, através da qual se abre espaço para a flexibilização e aceleração do tempo e do trabalho. A sobreimplicação é a crença no sobretrabalho, "no ativismo da prática, que pode ter como um de seus efeitos a dificuldade de se processar análises de implicações, visto que todo o campo permanece ocupado por um certo e único objeto" (LOURAU, 2004, apud COIMBRA; NASCIMENTO, 2007).

Como uma das aliadas dos conceitos da Análise Institucional, a cartografia possibilita colocar em trânsito a ideia de "desmontar o sistema de responsividade estímulo-resposta que considera o mundo dado e as ideias já formuladas" (POZZANA, 2013, p.329). Dessa forma, o método proposto auxilia a identificar e analisar as naturalizações produzidas no sistema educacional, como o fato de produzir respostas imediatas às demandas.

A Cartografia, da forma como é pensada pelo conjunto de autores elencados para a produção dessa escrita, começou a tomar forma na produção de Deleuze e Guattari e seguiu a perspectiva foucaultiana (PRADO FILHO; TETI, 2013). Para Pozzana (2013), interessa ao cartógrafo o acesso a uma trama que acompanha o ato de conhecer e de criar o mundo, a fim de se constituir uma aproximação com a construção do conhecimento e seus "efeitos políticos, éticos e estéticos” (p.327). Nesta direção, tanto pesquisador quanto participantes imbricam-se e transformam-se no decorrer da pesquisa. 
A cartografia auxilia na tentativa de identificar as linhas de força que atuam na instituição educação e em um de seus espaços privilegiados - a escola. Dessa forma, percebe-se que as linhas formam um emaranhado de forças que se deslocam constantemente, tensionando umas às outras e contribuindo com a sua potência para os acontecimentos.

A cartografia convida à invenção e à criação de outros mundos possíveis, ao encontro de conhecimentos e à produção de novas práticas. É um método que convoca ao movimento, à circulação de afetos e às travessias para a produção de novos territórios. A cartografia, como um método de pesquisa, apresentou alguns contornos que auxiliaram a organizar e a visualizar a atuação das linhas de força. A proposta consistiu em pensar a oficina como um dispositivo que faz ver e falar, um espaço no qual as linhas não cessam de atuar e de produzir novos sentidos. Dessa forma, a produção da maquinaria escolar e do seu entorno traçaram nesta pesquisa, três linhas de força que auxiliaram na análise: as linhas estética, política e jurídico- normativas. As linhas elencadas compõem a teia do dispositivo e encontram-se imbricadas em um jogo de saber-poder que inclui as subjetividades fabricadas pela maquinaria escolar.

\section{A oficina e suas linhas: um convite ao cuidado de si}

A definição de dispositivo apresentada por Deleuze (1999) consiste em um emaranhado composto por um conjunto multilinear com linhas de natureza diferente. Para o autor, cada linha "é quebrada, submetida a variações de direção, bifurcante e engalhada, submetida a derivações" (DELEUZE, 1999, s/p). Foucault (2014) lembra que o dispositivo está sempre inscrito em um jogo de poder, ligado a configurações de saber que dele nascem, mas também o condicionam.

As linhas estéticas foram pensadas como aquelas que indicam os modos de existência possíveis, com ênfase para a formulação de Michel Foucault que diz: a produção da vida como uma obra de arte. Essa construção possibilitou pensar nas multiplicidades e singularidades em pulsação na constituição dos sujeitos, assim como as intensidades e agenciamentos que se produzem frente às experiências de si com o mundo. Neste contexto, registraram-se a própria constituição de si e as produções subjetivas desencadeadas através das experiências de vida e de formação das professoras.

As linhas jurídicas normativas conformaram um campo permeado pelos discursos atravessados pelo Estado e sua regulamentação legislativa. O Estado se faz presente nos currículos, na formulação dos conteúdos mínimos para cada ciclo ou ano, nos regimentos escolares, na organização dos dias letivos em horas anuais, no ponto eletrônico, na falta de professores disponibilizados pelas gestões, entre tantos outros aspectos. Esta linha impacta diariamente as práticas produzidas na escola e, em conjunto com a rapidez e eficiência previstas pelo modelo neoliberal, produz sujeitos constantemente imbricados nas amarras da maquinaria escolar. 
As linhas políticas auxiliaram na análise da mobilização e ações coletivas das professoras, assim como o modo de se colocar no mundo, relacionando o pensamento e as práticas pedagógicas em sintonia com a reinvenção de si. Esta linha, assim como as demais, reorganização da classe docente frente às manifestações e reivindicações por melhores condições de trabalho e maior valorização da profissão.

No primeiro encontro as professoras foram convidadas a escolher uma fotografia ou objeto pessoal para incluir na sua apresentação ao grupo. A intenção foi conhecer o que movimenta esses corpos, valorizando as memórias e histórias consideradas especiais para as participantes. A proposta sustentou a possibilidade de que a fotografia ou objeto possa dizer algo sobre cada participante. Dessa forma, esta atividade "nos coloca um desafio qualitativo na pretensão de leitura, de escuta, de visualização dos movimentos, do dizível e do indizível, do que se mostra e do que se esquece, da produção de sentidos e significados individuais e coletivos" (OLIVEIRA et al., 2004, p.66).

Durante a atividade, algumas histórias se entrelaçavam, na medida em que todas as professoras trouxeram fotos ou objetos relacionados à sua família (em especial aos filhos) e a sua casa. Historicamente, há o registro do interesse das mulheres pela atividade docente, seja pela necessidade de mão de obra nas escolas, na medida em que os homens começam a ocupar trabalhos relacionados à urbanização e às cidades, seja pela docência caracterizar-se como uma profissão que permitiria às mulheres trabalhar um turno sem deixar de dedicarse também ao lar.

As histórias contadas a partir das fotografias revelaram algumas dimensões dos processos de subjetivação que fabricam os sujeitos, dimensionando o gênero e as expectativas sociais associadas à maternidade e à família. Foi possível conhecer um pouco sobre as suas trajetórias de vida e agenciou-se um espaço para que as memórias e experiências pudessem ser ressignificadas e compartilhadas, constituindo-se uma experiência coletiva.

No segundo encontro foram mapeadas as concepções das professoras a respeito do cuidado de si. Para iniciar o trabalho, realizou-se uma dança circular com a proposta de envolver o corpo em uma atividade que não fosse aquela prevista para o dia de trabalho. A dança se produziu como uma linha de fuga para que o corpo pudesse falar outras linguagens - a delicadeza dos movimentos desajeitados tentando "acertar o passo".

$\mathrm{Na}$ sequência, as professoras foram convidadas a produzir um painel com as suas concepções sobre o cuidado de si. Na composição, surgiram as expressões: estar bem; fazer o que dá prazer; chá; olhar; paz interior; meditação; ser egoísta; relaxar; escutar uma boa música; partilha; sabores; trocas; descobertas; escutar uma história engraçada. O cuidado de si e consequentemente, a oficina, aparecem atrelados a momentos de descontração e não necessariamente relacionados a um recolhimento ou ao repensar da prática docente, revisitando a trajetória pessoal.

Entretanto, encontraram-se alguns relatos que anunciam linhas de fuga. Uma das professoras ofereceu exemplos durante os encontros sobre como é possível transformar as práticas pedagógicas em verdadeiras experiências de si. A professora consegue reconhecer que o seu trabalho envolve questões muito mais complexas do que o ensino e aprendizagem 
de conteúdos pré-estabelecidos, ampliando o espaço para a sensibilidade e a criatividade no momento de construir as suas práticas pedagógicas. A abertura para o desejo e para as experiências de si também requer um trabalho do professor sobre si. A construção de práticas mais criativas e móveis possibilita que os estudantes desenvolvam um espaço potente para a sua expressão e produção de si como sujeitos autônomos e abertos a diferentes modos de vida na escola e no mundo.

No terceiro encontro, trabalharam-se aspectos sobre relações de gênero para pensar um cuidado de si atrelado às mulheres. Assim, o encontro poderia disparar discussões sobre como as mulheres se constituem historicamente e ocupam determinados lugares sociais. Como disparador para a oficina deste dia, assistiu-se ao curta-metragem "Acorda, Raimundo, acorda!". Nesse filme, a personagem principal, Raimundo, passa os dias cozinhando, limpando a casa, cuidando das crianças, costurando, entre outras tarefas domésticas. Sua companheira, por sua vez, trabalha como mecânica e vive constantemente estressada e reclamando sobre dinheiro.

O filme aborda de forma bem escrachada as relações naturalizadas entre homens e mulheres; porém, é possível problematizar alguns aspectos importantes. Propõe-se relações que sejam igualitárias entre homens e mulheres, o que não significa que a simples inversão de "papeis" construídos no imaginário social e naturalizados nas relações possa dar conta da questão. Pelo contrário, quando o filme representa de forma simplista a questão de gênero, não explora as possibilidades de formas diversas de como se desenvolvem os relacionamentos cotidianamente. Entretanto, o recurso cinematográfico gerou um clima diverso do que se esperava.

A constituição de si foi uma das linhas elencadas para dar um contorno a esta discussão e propõe que se volte o olhar para as formas como os sujeitos contemporâneos subjetivamse, ou seja, a forma de produção de si frente às demandas que emergem cotidianamente. Alguns fatos marcantes nas histórias foram compartilhados com o grupo e evidenciaram uma forte moral e ética com relação aos valores herdados da socialização familiar, comunitária e escolar.

Pode-se atribuir a centralidade destacada a alguns valores, em parte, às submissões vividas pelas mulheres, as quais compõem o processo de subjetivação. Essas submissões podem ser vividas de diversas formas e conferem um conjunto de "recomendações, exigências e pedidos intermináveis de alunos, chefes, colegas, pareceristas, filhos, parceiros, pais, maridos, padres, pastores, especialistas" (ZORDAN, 2016, p.475).

Através do tempo, observou-se a ampla produção de materiais que caracterizavam as professoras como mulheres que deveriam doar-se ao magistério, encontrando nele a sua vocação e a missão de educar os corpos jovens. Os interesses que mascaram esses enunciados e discursos acabam por contribuir para a produção de uma imagem da professora, a qual é divulgada para a população em geral, criando expectativas para uma conduta dedicada e submissa ao aparelho escolar. Por sua vez, dentro do espectro familiar, espera-se que a mulher-professora atenda às necessidades de sua família.

A naturalização de atribuições masculinas e femininas, o "modo de ser" homem ou mulher encontra-se arraigado nas estruturas sociais. A desvinculação desses papeis 
estereotipados necessita de uma ampla reflexão pessoal e atualização dos modos de vida colocados na contemporaneidade, os quais apresentam-se com marcas de antigas experiências sociais relacionadas ao gênero.

No quarto encontro, retomou-se a discussão sobre as relações de gênero com o intuito de oferecer um contorno mais amplo para a questão. Primeiro, retomou-se a atividade combinada para o dia: escrever sobre as memórias escolares a respeito das relações de gênero construídas na sua escolarização e como estas vivências refletem na prática atual em sala de aula. Todas participaram desse momento e contribuíram com suas histórias. Por vários momentos, foram produzidos agenciamentos entre as participantes, as quais conseguiram localizar na história da colega fatos similares às suas vivências, através de um agenciamento que produz conexões e um crescimento das dimensões de multiplicidade (DELEUZE; GUATTARI, 2011).

Cada professora compartilhou o seu relato a partir da singularidade de sua história, esta entendida como produto de um processo de subjetivação que é coletivo. Considerando a diferença de idade entre as professoras, percebeu-se que muitas cenas se repetem nas instituições familiares e educacionais, o que evidencia um aspecto de manutenção de algumas práticas ao longo dos tempos. Um dos aspectos relevantes é que metade do grupo teve sua escolarização em escolas católicas e, por vezes, femininas. As atividades constituíam-se como referentes "ao universo feminino", no qual se valorizava a aprendizagem de técnicas domésticas e etiqueta social.

Percebe-se que as linhas estéticas apontam para uma constituição de si que se apoia em referenciais considerados socialmente como femininos, a exemplo dos cuidados com o espaço doméstico e a vaidade. A classe social a qual estas professoras pertencem também é revestida por expectativas para essas mulheres, de forma que para as filhas de grupos sociais privilegiados, além do ensino comum, geralmente havia, também, o aprendizado do "piano e do francês que, na maior parte dos casos, era ministrado em suas próprias casas por professoras particulares, ou em escolas religiosas"4 (LOURO, 2006, p.446).

Em contrapartida, as participantes afirmam que, nas famílias, havia expectativas totalmente diversas para os homens, os quais eram considerados futuros chefes de família e aprendiam conteúdos que auxiliariam na sua entrada no mundo do trabalho. Todas as professoras relataram que suas experiências escolares e familiares foram atravessadas, de alguma forma pelo gênero, com exceção de uma participante que referiu que em sua família não havia distinções entre homens e mulheres.

Com relação à vida doméstica surgem alguns discursos relacionados aos problemas enfrentados pelos estudantes na sua escolarização, os quais são atribuídos, pelas professoras, às famílias. A instituição família é tratada como uma entidade quase sagrada, possuindo as respostas para o sucesso e insucesso da escolarização. Nesta visão, encontram-se os valores morais e patriarcais que acompanham as famílias tradicionais, visto que a maioria das professoras estudou em escolas religiosas e femininas.

A relação entre estas duas instituições - escola e família - não é comum apenas e este grupo de professoras. Seffner (2009) ilustra, através de seu diário de campo, algumas cenas cotidianas nas escolas, as quais relatam experiências sobre gênero e sexualidade. Nesse 
contexto, o autor afirma que a professora é um adulto de referência para os estudantes sendo importante haver o deslocamento da figura da tia ou segunda mãe. Ainda, segundo Seffner (2009), a professora é uma servidora pública, com autonomia para exercer a sua prática e pedagógica e está localizada fora do círculo familiar do aluno. Para o autor, a professora é um adulto educador que pode conversar sobre os mais diversos assuntos com os estudantes, mas de forma diversa da que conversaria com seus familiares. Neste sentido, ganham destaque os valores públicos e a ética e não apenas as crenças pessoais (SEFFNER, 2009).

Esse movimento parece atender as diversas forças que disputam o monopólio do poder. De um lado, há a forte herança cultural e uma moral que guiam a visão de mundo das classes que possuem maior poder aquisitivo, pois as elites lutam para não perder os privilégios de detenção do saber e não aceitam a escolarização proposta para as amplas camadas sociais. De outro lado, há o movimento impulsionado por um projeto de sociedade na qual a educação representa a possibilidade de civilizar o povo brasileiro. São valores presentes no século XIX e que, de alguma forma, permanecem tensionando sua presença de forma a mascarar-se em discursos pela defesa dos valores morais e familiares.

Na sequência do último encontro, tentou-se dar um contorno aos sabores e dissabores de se trabalhar na escola. A proposta consistiu em fotografar uma imagem que representasse um sabor e outra que indicasse um dissabor. A revisitação às cenas cotidianas possibilita o resgate da potência de algumas práticas desenvolvidas na escola, produzindo momentos que renovam o fôlego de se trabalhar nesse espaço. São momentos de contemplação dos saberes e fazeres que se produzem na escola fundamentais para não serem salientados apenas dissabores ou frustrações.

Mais de uma professora apontou o portão e os cadeados da escola como responsáveis por seu desencanto com o ambiente de trabalho. A escola é um espaço pensado especialmente para a vigilância dos corpos que a habitam. Foucault (2007) apresenta o princípio da clausura como regra de disciplina. Neste sentido, pode-se incluir a escola como um dos espaços de confinamento, com horários pré-determinados para entrada e saída que não podem ser rompidos sem uma justificativa que permita a autorização de alguém hierarquicamente responsável para tal.

A vigilância exercida sobre as escolas possibilita a produção de corpos dóceis e facilmente adaptáveis às situações a partir dos mecanismos construídos para gerir o tempo e o espaço. Aliada a esta vigilância, a disciplina apresenta-se como componente importante para a manutenção da ordem e dos comportamentos adequados ao espaço escolar. Machado (2014), em suas palavras iniciais, no livro Microfísica do Poder, apresenta a disciplina, assim pensada por Foucault, como "uma técnica, um dispositivo, um mecanismo, um instrumento de poder; são métodos que permitem o controle minucioso das operações do corpo, que asseguram a sujeição constante de suas forças e lhes impõem uma relação de docilidade-utilidade" (MACHADO, 2014, p.21).

Para Silva (2004, p.62), “o corpo é a superfície de inscrição das normas e valores de uma determinada sociedade; logo, é sobre ele que também se atualizarão as relações de poder" (p.62). Sobre os corpos estão dispostas as vigilâncias que se instauram entre as 
atividades desenvolvidas, desde a efetividade que deve ser realizada pelo funcionário público até às despretensiosas, passadas de diretoras e supervisoras enquanto a professora está em aula.

Em um contexto de controle das presenças e ausências das professoras que participam ou não de movimentos grevistas, o modelo neoliberal apresenta com maestria, um cenário de precarização e desgaste do âmbito público, apelando à terceirização dos serviços, de forma a atender às demandas do mercado e das elites empresariais. Este contexto gera um enfraquecimento da organização trabalhista assim como desmobiliza a categoria. Um reflexo desse panorama é a dificuldade que as professoras enfrentam para encontrarem forças e estratégias para participar de protestos e mobilizações. As linhas políticas imbricam-se com as linhas estéticas ao fazerem parte da fabricação de sujeitos reféns das amarras da maquinaria estatal e escolar.

As linhas jurídico-normativas ressurgem, por vezes, nos relatos das professoras e mostram toda a sua incidência nos discursos que regulam as práticas na escola. A Brigada Militar recorrentemente é chamada às escolas, seja para a realização de cursos "antidrogas", "educação para o trânsito" ou simplesmente para encerrar conflitos que se tornam inconciliáveis para as professoras. Este fato alerta para a produção de um contexto frágil de rede de apoio entre os sujeitos que compõem a escola, assim como o fortalecimento de sentimentos de pânico e medo, ambos também amplamente veiculados pela mídia. A fragilidade dessa rede que envolve a escola faz com que cresça um sentimento de impotência e expõe as professoras a situações em que não se sentem seguras.

Nesse último encontro as professoras também foram convidadas a oferecer uma palavra, para o grupo, que representasse alguns sentimentos despertados pela oficina. As palavras escolhidas foram: troca, acolhimento, reflexão e lembrança. Ficou a aposta de que as oficinas possam ter ressignificado os sentidos e instaurado possibilidades em devir para as práticas na escola. Além disso, as professoras deram pistas de que os encontros ofereceram brechas para que outros desejos e modos de vida possam se desenhar no seu percurso de docência. A busca por outros cursos que se somam ao trabalho na escola é uma tentativa de se reinventar e de criar caminhos que ofereçam novas experiências consigo e com o mundo.

\section{Considerações Finais}

Para a análise das situações colocadas por essa pesquisa foi importante traçar as linhas estéticas, políticas e jurídico-normativas que se constituíram como um mapa em processo. A análise das experiências e das linhas foram acompanhadas das histórias familiares memórias sobre a escolarização das professoras. Estas lembranças trouxeram para a oficina as demandas construídas pela naturalização das relações de gênero na sociedade. Assim, em meio ao cotidiano de trabalho, as professoras também se percebem envoltas com as atividades domésticas e familiares. As responsabilidades com os filhos e filhas, com a organização do espaço privado e com o planejamento das tarefas e do orçamento 
completam a jornada diária. Soma-se a esse fato a presença majoritária de mulheres na profissão docente, o que atribui determinadas expectativas com relação às práticas desenvolvidas.

Uma das preocupações dessa pesquisa foi justamente a de produzir uma experiência atenta às subjetividades e aos modos de vida produzidos na escola. Nesse processo, procurou-se introduzir alguns elementos relacionados ao cuidado de si que pudessem fazer parte das experiências e práticas desenvolvidas no espaço escolar, descobrindo experiências que pudessem colocar em questão a constituição de si como sujeito da educação. A constituição de si, nesse contexto, do mesmo modo se encontra imbricada com os processos de gênero construídos ao longo das vidas das professoras.

As ferramentas em Análise Institucional contribuíram, especialmente, com os conceitos de sobretrabalho, implicação, sobreimplicação e a tensão constante entre instituído-instituinte. Estes identificaram o trabalho na escola como respondendo às demandas de forma rápida, com poucos espaços para a reflexão e análise. As urgências produzidas pelo modelo neoliberal colocam o profissional em situações nas quais necessita mostrar-se incansavelmente eficiente e flexível.

Através das considerações propostas nessa pesquisa, coloca-se a necessidade de repensar as práticas pedagógicas e a renovação do modelo escolar, o qual se encontra cristalizado, com poucas mudanças em sua estrutura e repleto de conteúdos meramente reprodutivos. Defende-se a necessidade de construção de um espaço para que as professoras possam conhecer a si e exercitar o cuidado de si que também se estende ao cuidado com o outro.

Como sugestão, as formações propostas para as professoras poderiam transcender as ofertas de capacitações e reuniões que pouco contribuem com a efetiva prática em sala de aula. No dia a dia de trabalho, é comum se deparar com afirmações das próprias docentes sobre a distância que existe entre os cursos propostos pelas gestões e o trabalho com os estudantes. Nesse sentido, a proposta consiste em multiplicar os espaços para um trabalho que inclua a produção de subjetividade.

São válidas as rodas de conversa com compartilhamento de experiências e momentos de reflexão sobre si, as quais contemplam a inclusão do cuidado de si. Este conceito mostrou-se poroso para a proposta desenhada nessa pesquisa e colocou-se como um parceiro para repensar as práticas desenvolvidas no espaço escolar. As formações que incluem o uso das histórias orais e de vida, as fotografias, o cinema, a literatura, sempre se demonstraram como ferramentas enriquecedoras, tanto para a constituição de si quanto para a reinvenção dos modos de estar em sala de aula. Para isso, é fundamental revisar a carga horária de trabalho desenvolvida nas escolas, a fim de se construir espaços mais democráticos e inventivos para as crianças e adolescentes.

Propõem-se interrogar as práticas que são construídas ao longo da trajetória docente e compartilhar mais momentos com os pares. Dessa maneira, a construção de uma rede coletiva de apoio e de análise das demandas diárias poderia fortalecer o trabalho na escola. A produção dessa experiência exigiu cuidado, delicadeza e tempo para o acontecimento. $\mathrm{O}$ cuidado de si viabilizou experiências compartilhadas, uma revisitação à história de cada um 
e o conhecimento de si para agir na realidade existente. Dessa forma, a escola pode abrir espaços para produções mais criativas e territórios existenciais mais livres que acolham outros modos de vida possíveis.

\section{Notas}

1. Em caso de aceite as autoras incluirão detalhes sobre a dissertação.

2. Para mais detalhes indicam-se as publicações: OLIVEIRA, D.A.; VIEIRA, L.M.F. (orgs.). Trabalho docente na Educação Básica no Brasil - Sinopse do Survey. Universidade Federal de Minas Gerais, Grupo de Estudos Sobre Política Educacional e Trabalho Docente. Belo Horizonte, 2010; e AGÊNCIA BRASIL. Saúde do professor está ligada a boas condições de saúde. Disponível em: <http://agenciabrasil.ebc.com.br/educacao/noticia/2015-10/saudedo-professor-esta-ligada-boas-condicoes-de-trabalho-diz-cnte>. Acesso em: 15 de abril. 2016.

3. A pesquisa foi submetida à apreciação e aprovada pelo Comitê de Ética em Pesquisas do Instituto de Psicologia da Universidade Federal do Rio Grande do Sul. A pesquisa está de acordo com as Diretrizes e Normas Regulamentadoras de Pesquisa envolvendo Seres Humanos, referente à Resolução 466/12 do Conselho Nacional de Saúde. Cada participante recebeu uma via do Termo de Consentimento Livre Esclarecido que orientava a respeito dos aspectos éticos da pesquisa.

4. Não se fala de uma experiência universal, mas de registros históricos referentes às escolarizações de meninas no Brasil.

\section{Referências Bibliográficas}

COIMBRA, C. M. B.; NASCIMENTO, M. L. Sobreimplicação: práticas de esvaziamento político? In E. M. M. ARANTES, M. L. NASCIMENTO; T. M. G. FONSECA (Orgs.). Práticas psi inventando a vida. Rio de Janeiro: EdUFF, 2007.

DELEUZE, G. Que és un dispositivo? In: BALIBAR, Etinenne; DREYFUS, Hubert; DELEUZE, Gilles et al. Michel Foucault, filósofo. Barcelona: Gedisa, 1999.

DELEUZE, G.; GUATTARI, F. Mil Platôs - Capitalismo e Esquizofrenia. Vol.1. São Paulo: editora 34, 2011.

FOUCAULT, M. A hermenêutica do sujeito. São Paulo: Martins Fontes, 2014.

História da Sexualidade - O cuidado de si. Vol.3. Trad. Maria Thereza da Costa Albuquerque. Rio de Janeiro: Edições Graal, 1985.

A escrita de si. In: Ética, sexualidade, política - Ditos e Escritos V. $3^{\text {a }}$ ed. São Paulo: Forense Universitária, 2012.

A ética do cuidado de si como prática da liberdade. Ética, sexualidade, política - Ditos e Escritos V.

$3^{\mathrm{a}}$ ed. São Paulo: Forense Universitária, 2012.

Vigiar e Punir. 34ª edição. Rio de Janeiro: Vozes, 2007.

GALVÃ̃, B.A. A ética em Michel Foucault: Do cuidado de si à estética da existência.

Revista Intuito, Porto Alegre, v.7, n.1, pp.157-168, jun. 2014.

GROS, F. À propos de l'herméneutique du sujet. In: LE BLANC, G. \& TERREL, J. Foucault au Collège de

France: un itinéraire. Trad. Alessandro Francisco. Bordeaux: Presses Universitaires de Bordeaux, 2003.

LARROSA, J. Notas sobre a experiência e o saber de experiência. Revista Brasileira de Educação, n.19, Jan./Fev./Mar./Abr. 2002.

LIBERATO, M.T.C.; DIMENSTEIN, M. Experimentações entre dança e saúde menta. Fractal: Revista de

Psicologia, v.21, n.1, p.163-176, jan./abr. 2009.

LOURAU, R. Análise Institucional e práticas de pesquisa. Rio de Janeiro: editora da UERJ, 1993. 
LOURO, G.L. Mulheres na sala de aula. In: LOURO, G.L. PRIORE, M.D.; BASSANEZI, C. (orgs.). História das mulheres no Brasil. São Paulo: editora Contexto, 2006.

MACHADO, R. Por uma genealogia do poder. In: FOUCAULT, M. Microfísica do poder. Rio de Janeiro: Paz e Terra, 2014.

OLIVEIRA, V.F.; OLIVEIRA, V.F.; FABRÍCIO, L.E.O. Imagens na pesquisa com professores: o oral e a fotografia. Educação, v.29, n.1, 2004.

POZZANA, L. A formação do cartógrafo é o mundo: corporificação e afetabilidade. Fractal, Rev. Psicol., v.25, n.2, p.323-338, mai./ago. 2013.

PRADO FILHO, K.; TETI, M. M. A cartografia como um método para as Ciências Sociais e Humanas. Barbarói, Santa Cruz do Sul, n.38, p.45-59, jan./jun. 2013.

PRADO FILHO, K.P. Considerações acerca do cuidado de si mesmo no contemporâneo. In: TEDESCO, S.; NASCIMENTO, M.L. (orgs.). Ética e subjetividade - novos impasses no contemporâneo. Porto Alegre: Sulina, 2009.

ROMAGNOLI, R. C. A cartografia e a relação pesquisa e vida. Psicologia \& Sociedade, v.21, n.2, p.166173. 2009.

SEFFNER, F. Um bocado de sexo, pouco giz, quase nada de apagador e muitas provas: cenas escolares envolvendo questões de gênero e sexualidade. Estudos Feministas, Florianópolis, v.19, n.2, pp.336, mai./ago. 2011.

SILVA, R.N. A Dobra Deleuziana: Políticas de Subjetivação. Revista do Departamento de Psicologia (UFF), Niterói, v.16, n.1, p.55-75, 2004.

VEIGA-NETO, A. Governamentalidades, neoliberalismo e educação. In: BRANCO, G.C.;

VEIGA-NETO, A. (orgs.). Foucault - filosofia \& política. Belo Horizonte: Autêntica, 2013.

ZORDAN, P. Ortopedoxia: exercícios e experiências em torno de um corpo. In: Anais do $\mathbf{2 5}^{\circ}$ Encontro da ANPAP - Arte: seus espaços e/em nosso tempo. Porto Alegre: Associação Nacional de Pesquisadores em Artes Plásticas, 2016.

\section{Correspondência}

Caroline Foletto Bevilaqua: É psicóloga, pedagoga e Mestre em Psicologia Social e Institucional pela Universidade Federal do Rio Grande do Sul. Atualmente trabalha como professora PEB I, na prefeitura municipal de Canoas, Rio Grande do Sul, Brasil.

E-mail: caroline.bevilaqua@canoasedu.rs.gov.br

Rosemarie Gartner Tschiedel: É professora associada do Instituto de Psicologia, Departamento de Psicologia Social e Institucional, coordenadora do Núcleo de Estudos e Pesquisas em Processos Institucionais, Coletivos e de Subjetivação - Programa de Pós-graduação em Psicologia Social e Institucional - Universidade Federal do Rio Grande do Sul - UFRGS.

E-mail: rosetschiedel@gmail.com

Texto publicado em Currículo sem Fronteiras com autorização das autoras 